\title{
Radiographic Examination
}

National Cancer Institute

\section{Source}

National Cancer Institute. Radiographic Examination. NCI Thesaurus. Code C128940.

A radiographic procedure using the emission of penetrating energy waves to form an image of the structure penetrated by the radiation. 